\title{
Proposed personal green mobility (PGM) tricycle
}

\author{
Kazufumi UDA* \\ *Kanagawa Institute of Technology \\ 1030 Shimo-Ogino, Atsugi, Kanagawa, 243-0292, Japan \\ E-mail: uda-kf@cco.kanagawa-it.ac.jp
}

Received: 13 December 2016; Revised: 26 January 2017; Accepted: 14 March 2017

\begin{abstract}
Recently, the replacement of chemical resources with natural resources has been strongly desired for the recovery of ecosystems. Considering this, we have been focusing on bamboo fibers as a structural member of vehicles. Because bamboo can be returned to the soil after its use, its environmental impact is much lower than that of recyclable metals and plastics. If the industrial application of bamboo is expanded and the regeneration of bamboo forests is accordingly promoted, its environmental impact can be reduced. In previous studies, we developed a bamboo-fiber-reinforced laminated plate (BFRLP) with improved specific rigidity and specific strength by arbitrarily arranging and laminating bamboo fibers. Using the BFRLPs as a structural material, we also developed an ultra-small one-person electric tricycle called the personal green mobility (PGM) tricycle to help the elderly travel and go shopping in limited areas. A carry-bag-type design was adopted to realize a lightweight PGM tricycle with a simple structure. And, we also developed a new material by joining reinforced corrugated fiberboard (RCF) and BFRLPs and called it a green composite hybrid material (GCHM). The structural members of the new lightweight PGM tricycle are made of bamboo, vegetable fiber materials, and RCF. It can be assembled and repaired at home by the elderly and is capable of traveling at an ultralow speed using six AA-size rechargeable batteries. As a national policy, towns where the elderly can lead a pleasant life should be built. The biodegradable PGM tricycle using vegetable fiber materials is proposed as a new alternative in a society based on the vehicle.
\end{abstract}

Keywords : Personal green mobility, PGM, Green composite hybrid materials, GCHM, Natural returning, Soil

\section{Introduction}

Vehicles currently have various power sources, such as gasoline, diesel, electricity, and fuel cells. Although the environmental performance of vehicles has markedly improved owing to technical advances, the improvement of infrastructure related to electric vehicles is desired (Yearbook for JSAE, 2015a). With the Road Traffic Policy Organic Act by the Ministry of Land, Infrastructure, Transport and Tourism in Japan (Road Traffic Policy Organic Act, 2013) as a background, it is desirable to plan cities in which residents can efficiently travel with ultra-small vehicles having a high mobility used as a means of transportation for the elderly" (Yearbook for JSAE, 2015b). The number of such one-person vehicles that can run on public roads has been increasing in recent years.

With the aim of helping the elderly travel in limited areas excluding public roads, we have developed an ultra-small low-speed one-person electric tricycle, called a personal green mobility (PGM) tricycle (Takahashi and Uda, 2012) (Uda et al., 2013-2014). Initially, our originally developed material called a bamboo-fiber-reinforced laminated plate (BFRLP) (Uda, 2015) was used as the structural member of the vehicle body. Later, a new biodegradable green composite hybrid material (GCHM) was developed by gluing BFRLPs and reinforced corrugated fiberboard (RCF) to further reduce the weight of the vehicle body and used in the PGM tricycle. Where, the bamboo is used as a laminate lumber for a framework (Dia Bamboo Products Catalogue, 2017) of a door. Recently, bamboo fiber materials have been studied as door trim and mat materials of a luggage room of a vehicle (Fujikawa et al., 2006) (Amada, 1998), and their utilization (Abhijit P, et al., 2000) (Tokoro et al., 2008) (Ramirez F. et al., 2011) has progressed. As far as an author gets to know, the example of research which applied the GCHM to the structural member of the vehicle is not found. 
Then, the PGM tricycle has been adopted as a topic of product-based learning (PBL) for the education of students at Kanagawa Institute of Technology (KAIT). It is small, lightweight, and inexpensive, uses biodegradable GCHM for the body structure, and can be assembled and repaired at home by the elderly. A vision of a society based on the PGM tricycle is proposed at the end of this paper.

\section{Nomenclature}

$\begin{array}{lll}b & : \text { Width of specimen } & {[\mathrm{mm}]} \\ E^{*} & : \text { Pseudo longitudinal elastic modulus } & {[\mathrm{MPa}]} \\ E^{*} I^{*} & : \text { Pseudo bending rigidity } & {\left[\mathrm{MPa}-\mathrm{mm}^{4}\right]} \\ h & : \text { Height of specimen } & {[\mathrm{mm}]} \\ I^{*} & : \text { Pseudo second moment of inertia } & {\left[\mathrm{mm}^{4}\right]} \\ L & : \text { Span of specimen } & {[\mathrm{mm}]} \\ M & : \text { Bending moment } & {[\mathrm{N}-\mathrm{m}]} \\ M_{f} & : \text { Fractured bending moment } & {[\mathrm{N}-\mathrm{m}]} \\ P & : \text { Load } & {[\mathrm{N}]} \\ t & : \text { Thickness of specimen } & {[\mathrm{mm}]} \\ y & : \text { Bending deflection } & {[\mathrm{mm}]} \\ y_{\text {max }} & : \text { Maximum bending deflection } & {[\mathrm{mm}]} \\ y_{n} & : \text { Non-dimensional deflection }\left(=y / y_{\text {max }}\right) & {[-]} \\ Z & : \text { Section modulus } & {\left[\mathrm{mm}{ }^{3}\right]} \\ \sigma_{f} & \left.: \text { Fracture strength (= } M_{f} / Z\right) & {[\mathrm{MPa}]} \\ \sigma_{f 1} & : \text { Fracture strength for double wall of RCF } & {[\mathrm{MPa}]} \\ \sigma_{f 2} & : \text { Fracture strength for triple wall of RCF } & {[\mathrm{MPa}]} \\ \theta_{f} & : \text { Fiber orientation angle (for BFRLP and or RCF) } & {[\mathrm{degree}]} \\ & & \\ \text { BFRLP } & : \text { Bamboo Fiber Reinforced Laminated Plate } & \\ \text { GCHM } & : \text { Green Composite Hybrid Material } & \\ \text { PGM } & : \text { Personal Green Mobility } & \\ \text { RCF } & : \text { Reinforced Corrugated Fiberboard } & \\ \text { KAIT } & : \text { Kanagawa Institute of Technology } & \end{array}$

\section{Current status of green mobility}

"Green" indicates the reduction of adverse effects on the global environment and "mobility" indicates a means of transportation. Therefore, "green mobility" refers to bicycles as a means of transportation with low environmental impact (Material of Green Mobility, 2015). Moreover, the Green Mobility Research Institute, Institutes of Innovation for Future Society, Nagoya University (GREMO, 2016) strongly recognizes green innovation as an urgent task in Japan and is promoting research on a safe and secure transportation system with low environmental impact using green mobility on the basis of industry-government-academia collaboration and international cooperation (GREMO, 2016). More than 40 local cities in Japan are intensively tackling the development of healthy and happy cities called Smart Wellness Cities (Material of Smart Wellness City, 2015) in which people can walk around safely, as well as the improvement of urban transportation networks by referring to the case of Freiburg in Germany.

\section{Design requirements for PGM tricycle}

Table 1 shows the main design requirements for the PGM tricycle in its development stage. The design value of $85 \mathrm{~kg}$ for the withstand load of PGM was considered as follows; the tare of PGM is $5 \mathrm{~kg}$ and the body weight of a driver is $80 \mathrm{~kg}$. The highest priority in a work environment is to ensure a safe area. The work area required to smoothly assemble the PGM tricycle was determined to be approximately $5 \mathrm{~m}^{2}$. In this small area, the movement of the worker is minimized and the arrangement and tidying up of machines and parts can be completed in a short time. 
Table1 Design concept for PGM. Considering the needs of the elderly, the proposed PGM tricycle should be inexpensive and be used as a transportation device on flat roads, including shopping areas, in department stores, and inside houses but not on public roads. The parts of the PGM tricycle are joined by Japanese timberwork technology called Kigumi (Carpenters' Tools Study Group, 2014). We attempted to simplify the structure by reducing the number of parts and adopting built-in structures so that the elderly can assemble and maintain the tricycle at home.

\begin{tabular}{|c|c|c|c|}
\hline Item & Contents & Item & Contents \\
\hline Material & $\begin{array}{l}\text { Bamboo single plate, } \\
\text { BFRLP and RCF }\end{array}$ & Running velocity & $\begin{array}{l}1 \mathrm{~km} / \mathrm{h} \text { or less } \\
\text { (Public road cannot running) }\end{array}$ \\
\hline Material cost & 20,000 yen or less & $\begin{array}{l}\text { Minimum } \\
\text { turning radius }\end{array}$ & $0.5 \mathrm{~m}$ or less \\
\hline $\begin{array}{l}\text { Allowable maximum } \\
\text { authorized payload }\end{array}$ & $85 \mathrm{~kg}$ & Carrying performance & $\begin{array}{l}\text { Baggage carrying in in an } \\
\text { airplane is possible }\end{array}$ \\
\hline Target tare & $5 \mathrm{~kg}$ & $\begin{array}{l}\text { Decomposition } \\
\text { assembly time }\end{array}$ & $\begin{array}{l}\text { Less than five minute / } \\
\text { one person }\end{array}$ \\
\hline $\begin{array}{l}\text { Maximum } \\
\text { approach angle }\end{array}$ & 2 degree & $\begin{array}{l}\text { Assembly and } \\
\text { maintenance }\end{array}$ & Possible at home \\
\hline $\begin{array}{l}\text { Joint type } \\
\text { of member }\end{array}$ & $\begin{array}{l}\text { Imitated technology of } \\
\text { Kigumi in Japan }\end{array}$ & Run place & $\begin{array}{l}\text { Flat way on indoor and or } \\
\text { outdoor }\end{array}$ \\
\hline
\end{tabular}

\section{Features of GCHM \\ 4.1 Preparation of GCHM}

Considering the current status of green mobility, we are developing lightweight high-rigidity materials using vegetable fiber materials. In this study, RCF (brand name: Reinforced Corrugated Fiberboard for Heavy Export Packing) (Sanyo Package System Product Catalogue, 2016) and BFRLPs were glued and laminated using glue for wood to develop the GCHM, as shown in Fig. 1. The target thickness of the adhesion layer was set to $t^{*}=0.05 \mathrm{~mm}$. After the BFRLPs and RCF were glued using the glue to form a GCHM, it was left to stand for 10 min then pressed using a set of steel plates, as shown in Fig. 1, and dried at room temperature $\left(20{ }^{\circ} \mathrm{C}\right)$ with a humidity of $40 \%$ for $24 \mathrm{~h}$. The average thickness of the adhesion layer was confirmed to be within $\pm 10 \%$ of the target value using a feeler gauge, as shown in Fig. 2. The developed GCHM is shown in Fig. 3. The laminated structure of the GCHM was determined to be as follows considering its surface strength and waterproof property. The fiber orientation angle $\theta_{f}$ is $0^{\circ}$ in the longitudinal direction of the GCHM. Hereafter, the angle symbol $\left[^{\circ}\right.$ ] is omitted and $\theta_{f}$ is described as [upper layer/lower layer]; for example, when two layers are laminated, the fiber orientation angle is described as $\theta_{f}=[0 / 0]$. The outermost layers are cross-ply BFRLPs with $\theta_{f}=[0 / 90]$, and two or three RCF layers with $\theta_{f}=[0 / 0]$ or [0/0/0] were laminated between the BFRLPs. A cutter knife and a laser beam machine were used to fabricate the GCHM.

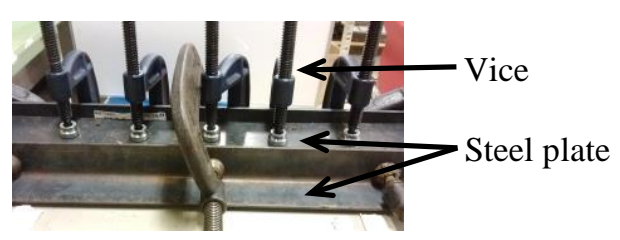

Fig.1 Adhesion work for GCHM using vices and steel plates and dried for $24 \mathrm{~h}$.

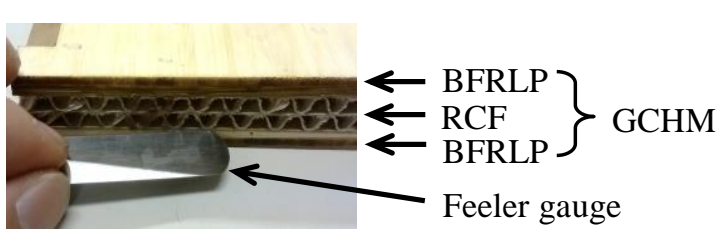

Fig.2 Confirmation for adhesion layer thickness using feeler gauge (Example of used for side member).

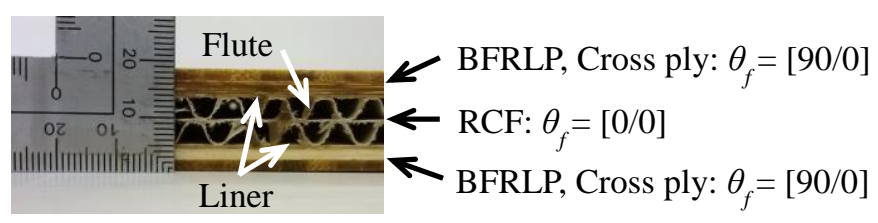

Fig.3 Construction of GCHM (Double wall of RCF). BFRLP of $\theta_{f}=[0 / 90]$ is arranged in common with double and or triple wall of RCF at both the outsides of GCHM. 
The characteristics of the GCHM were determined on the basis of elementary beam theory. As the material characteristics, the pseudo bending rigidity $E^{*} I^{*}$ was determined by a cantilever bending experiment, as shown in Fig. 4 and the fracture strength $\sigma_{f}$ was determined by a three-point bending experiment under a load concentrated at the center of span, as shown in Fig. 5. In the cantilever bending experiment, the span $L$ was $350 \mathrm{~mm}$, the width of the specimen $b$ was $50 \mathrm{~mm}$, and the plate thicknesses $t$ were $18 \mathrm{~mm}$ for the specimen with double wall of RCF and $24 \mathrm{~mm}$ for the specimen with triple wall of RCF. In the three-point bending experiment, $L$ was $400 \mathrm{~mm}$ and $b$ and $t$ were the same as those in the cantilever bending experiment.

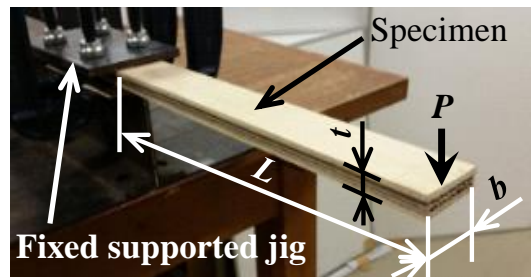

Fig. 4 Experimental set up for cantilever bending.

Lumped load, $P$, was applied at the free end.

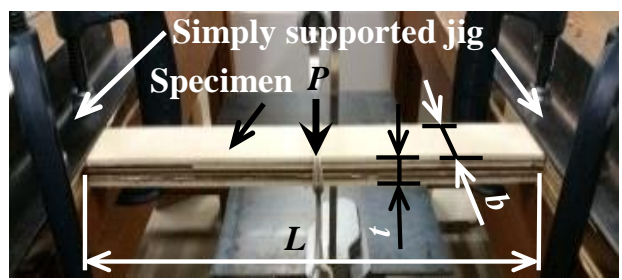

Fig. 5 Experimental set up for three-point bending. Lumped load, $P$, was applied at the center of span.

\subsection{Pseudo bending rigidity}

To determine $E^{*} I^{*}$ for the GCHM, a cantilever bending load of $P=29.4 \mathrm{~N}$ was applied to the free end of the specimen, as shown in Fig. 4, and the bending deflection $y$ and the maximum bending deflection $y_{\max }$ were measured. The non-dimensional bending deflection $y_{n}$ is given by

$$
y_{n}=\frac{y}{y_{\max }}
$$

Figure 6 shows plots of $y_{n}$ obtained in the cantilever bending experiment and the bending deflection curve obtained from elementary beam theory. $E^{*} I^{*}$ for the GCHM is calculated using the following equation for the case when the difference between the experimental and theoretical values is small.

$$
E^{*} I^{*}=\frac{P L^{3}}{3 y_{\max }},
$$

where $E^{*}$ is the pseudo longitudinal elastic modulus and $I^{*}$ is the pseudo second moment of inertia. We obtained $E_{1}{ }^{*} I_{1}{ }^{*}$ $=70.1 \mathrm{MPa} \cdot \mathrm{mm}^{4}$ for the specimen with double wall of RCF and $E_{2}{ }^{*} I_{2}{ }^{*}=120.2 \mathrm{MPa} \cdot \mathrm{mm}^{4}$ for the specimen with triple wall of RCF as tentative values.

\subsection{Fracture strength}

To determine $\sigma_{f}$ for the GCHM, a three-point bending experiment was performed, as shown in Fig. 5. $y$ was measured at the opposite end to the loading point for different loads, and a bending moment-bending deflection (M-y) diagram was obtained, as shown in Fig. 7. $\sigma_{f}$ is given by

$$
\sigma_{f}=\frac{M_{f}}{Z}
$$

where $M_{f}$ is the fracture bending moment and $Z$ is the section modulus. 
As shown in Fig. 3, the cross-sectional shape of the GCHM is complicated and has an irregular form. Here, the cross section of the GCHM is tentatively assumed to be a solid rectangle with width $b$ and height $h$. $Z$ is given by

$$
Z=\frac{b h^{2}}{6}
$$

Similarly, $I^{*}$ in Eq. (2) is tentatively assumed to be that of a solid rectangle. The number of GCHM specimen is three, respectively. The experimental results and these mean-value, $\sigma_{f}$, are shown in Table 2 . The mean-value of fracture strength of the specimen with double wall RCF layers, $\sigma_{f 1}$, was $17.3 \mathrm{MPa}$ and that of the specimen with triple wall RCF layers, $\sigma_{f 2}$, was $11.5 \mathrm{MPa}$. It is thought that the cause of the variation in every value $\sigma_{f}$ value is mainly based on the individual specificity when the specimen was manufactured. These are used as examples of measured values.

Table 2 Fracture strength of GCHM with double and or triple wall of RCF. $\sigma_{f 1}$ was rather than $\sigma_{f 2}$.

\begin{tabular}{c||c|c}
\hline \hline \multicolumn{1}{c||}{ Construction of GCHM specimen } & $\begin{array}{c}\text { Every results, } \\
\sigma_{f}[\mathrm{MPa}]\end{array}$ & $\begin{array}{c}\text { Average-value, } \\
\sigma_{f 1} \text { and or } \sigma_{f 2}[\mathrm{MPa}]\end{array}$ \\
\hline \hline With double wall of RCF $\left(\theta_{f}=[0 / 90 / 0 / 0 / 90 / 0]\right)$ & $15.6,16.3,20.1$ & $\sigma_{f 1}=17.3$ \\
\hline With triple wall of RCF $\left(\theta_{f}=[0 / 90 / 0 / 0 / 0 / 90 / 0]\right)$ & $11.8,9.5,13.3$ & $\sigma_{f 2}=11.5$ \\
\hline
\end{tabular}

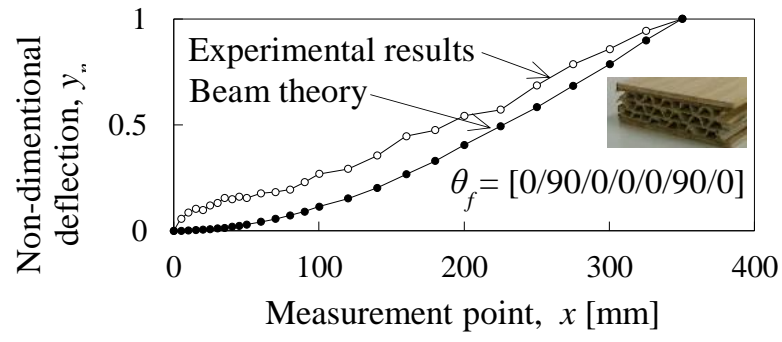

Fig.6 Non-dimensional deflection, $y_{n}$, obtained in the cantilever bending experiment and the deflection curve obtained from beam theory were shown.

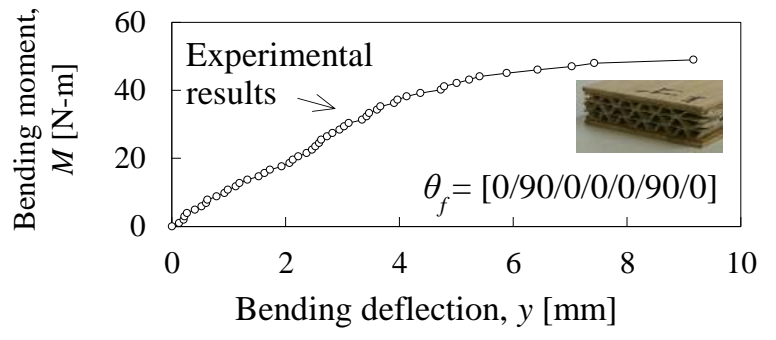

Fig.7 Bending moment and deflection obtained in the three-point bending experiment.

The fractured states of the specimens are shown in Fig. 8. For the specimen with double wall of RCF [Fig. 8(a)], the double wall of RCF separated at the sidewall, and the BFRLPs fractured. For the specimen with triple wall of RCF [Fig. 8(b)], however, the BFRLPs fractured at the loading point, but the RCF layers did not separate. Because $E^{*} I^{*}$ for the beam was larger for the specimen with triple wall of RCF than for the specimen with double wall of RCF, $\sigma_{f}$ was expected to be larger for the specimen with triple wall of RCF than for the specimen with double wall of RCF. However, the opposite result was obtained. BFRLP of $\theta_{f}=[0 / 90]$ is arranged in common with double and or triple wall of RCF at both the outsides of GCHM. It is thought that the strength of the whole GCHM cannot be easily dependent on the strength of a unity for a BFRLP. When RCF became triple wall layers, it is thought that board thickness became thick, $I$ value became large and rigidity became high. However, Liner arranged by one layer to the board thickness direction rather than double wall of in triple wall, a wave like hollow was increased. Then, the rigidity of RCF falls and bending deformation also becomes large. As a result, it is thought that the strength of RCF of triple wall was reduced. Moreover, this is because the adhesion strength between the RCF and the BFRLPs obtained with the current technology was locally small at some positions and the fracture pattern was not uniform.

Furthermore, the cross sections of the sidewalls and end planes were open as a result of cutting the RCF, which may have decreased their strength. Therefore, a technology for improving the strength and rigidity of the sidewalls and end planes of the specimens and structural members, for example, performing closed-section processing on channel-shaped members, should be established. In addition, the adhesion strength of the adhesion surface should be improved. 


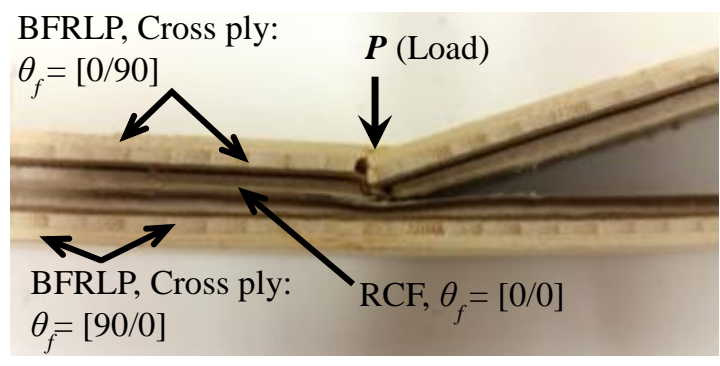

(a) Fractured portion for $\theta_{f}=[0 / 90 / 0 / 0 / 90 / 0]$.

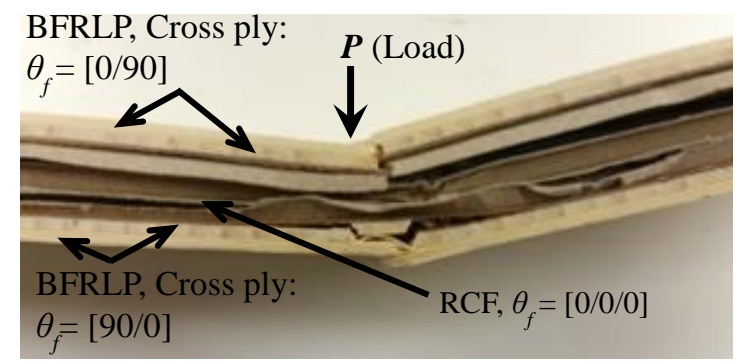

(b) Fractured portion for $\theta_{f}=[0 / 90 / 0 / 0 / 0 / 90 / 0]$.

Fig.8 Fractured specimens with double wall of RCF [Fig. 8 (a)] and with triple wall of RCF [Fig.8 (b)] under three-point bending were shown. For the specimen with double wall of RCF, the RCF separated at the sidewall, and the BFRLPs fractured. For the specimen with triple wall of RCF, however, the BFRLPs fractured at the loading point, but the RCF layers did not separate.

\section{Application of GCHM to PGM tricycle 5.1 Concept of PGM tricycle}

To confirm the above findings, the GCHM was applied to the PGM tricycle (PGM-2015), which was entered into the pico-EV Eco-Challenge competition sponsored by the Japan Society of Mechanical Engineers (JSME) (pico-EV Eco Challenge 2015, 2015). The outline of the competition is as follows: (1) The competition is a design activity open to students. (2) The vehicle is required to run around an oval course of $70 \mathrm{~m}$ for $30 \mathrm{~min}$ using six AA rechargeable dry cell batteries (1.2 V, $1900 \mathrm{mAh}$ ). (3) The vehicle should be ultra-small, lightweight, for one person, and have three or more wheels. PGM-2015 was designed and developed in accordance with the rules of the competition.

The design concept of PGM-2015 is as follows: (1) It is an ultra-small and lightweight vehicle designed for the elderly, which has low maintenance and management costs, can travel at an ultralow speed, and is not used on public roads. (2) It can be carried on an airplane.

Assuming the target tare of PGM-2015 to be $5 \mathrm{~kg}$ and the weight of the driver to be $80 \mathrm{~kg}$, PGM-2015 was designed with the consideration of $E^{*} I^{*}$ and $\sigma_{f}$. A structure with a simple design was adopted to facilitate the transport and assembly procedures, and the GCHM was used to reduce the weight of the vehicle body. Figures 9 and 10 show the dimensions and mechanism of the developed carry-bag-type PGM-2015, respectively. To reduce the number of parts and realize a simple structure, handles were built into the structure.

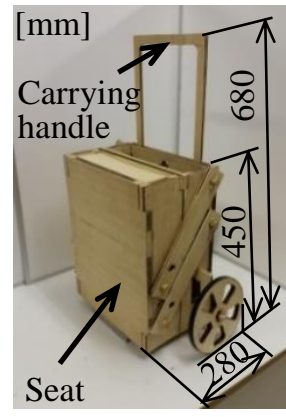

(a) Carry bag form.

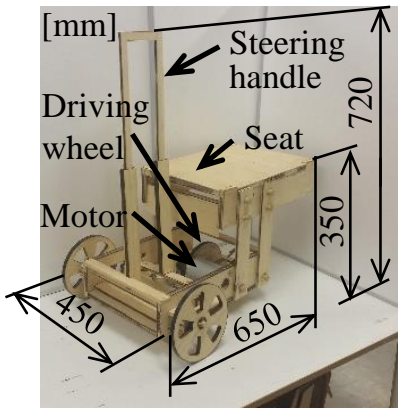

(b) Running form.

Fig.9 Dimensions of PGM-2015 were shown. For carry bag, height is $680 \mathrm{~mm}$ and depth is $280 \mathrm{~mm}$. For running form, height is $720 \mathrm{~mm}$, depth is $650 \mathrm{~mm}$ and width is $450 \mathrm{~mm}$.

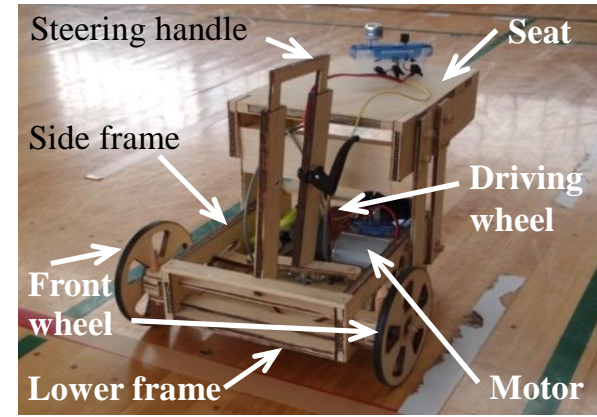

Fig.10 Mechanics of PGM-2015 were as follows; the driver seated on the seat, the driving wheel was rotated by the motor, then, the PGM was traveling by the steering handle.

\subsection{Measures for body weight reduction using GCHM and their effect}

The weight of the vehicle body is considered to be reduced when the GCHM is used, even if only partially, compared with when only BFRLPs are used as a structural material. Therefore, the GCHM was used for structural members with a large weight, for example, the joints between the lower frame and the side plate, the seat, and the side 
frame in the front body. Figure 11 shows the seat and the side frame made of the GCHM. The weight of the GCHM with double or triple wall RCF was compared with that of the BFRLP of the same thickness. It was found that the GCHM was about $50 \%$ lighter than the BFRLP. In this study, the total weight of PGM-2015 was reduced by $21 \%$ to $4.2 \mathrm{~kg}$ by using the GCHM. Thus, the weight of PGM-2015 can be reduced, while maintaining its rigidity, by using the GCHM for appropriate parts.

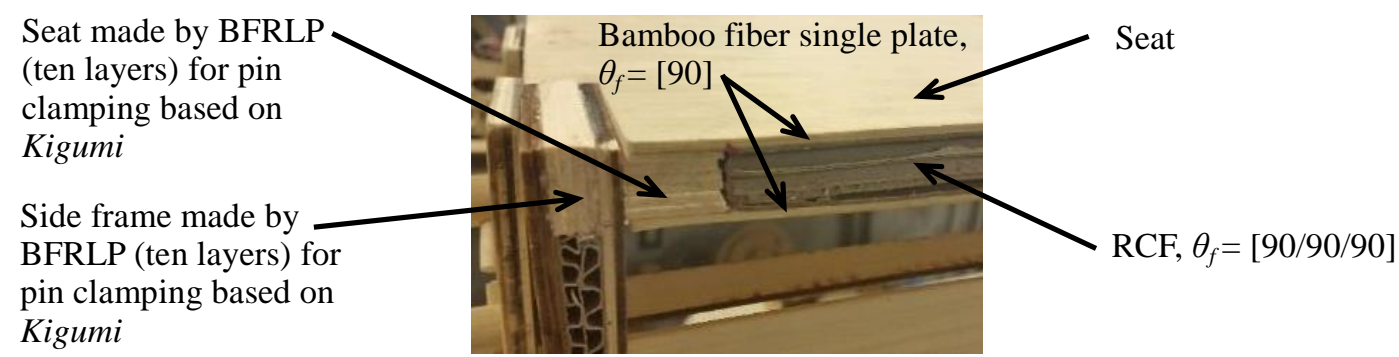

Fig.11 Structural mechanism of the seat and side frame using GCHM was shown. The seat and side frame made by BFRLP for pin clamping were based on Kigumi.

\subsection{Technique for joining structural members and evaluation of their rigidity}

Our previous PGM tricycles (Takahashi and Uda, 2012) (Uda et al., 2013 - 2014) were fabricated by using the Japanese traditional timberwork technology called Kigumi (Carpenters' Tools Study Group, 2014) to join wooden material members. In addition to BFRLPs, RCF is used to reduce the weight of the body structure of the PGM tricycle developed in this study. The structural members were joined using bamboo pins similarly to in Kigumi. As shown in Fig. 12, ten BFRLP laminated layers were used for the parts, where structural members were joined using a pin. To confirm the strength and rigidity of the PGM tricycle body, the static bending deflection of the frame with a driver on PGM-2015 was experimentally determined. It was found that the bending deflection was $1 \mathrm{~mm}$. Neither deformation nor fracture was observed in each part. Thus, it was clarified that the GCHM is effective in terms of rigidity and strength. As shown in Fig. 13, the measured ground clearance was $47 \mathrm{~mm}$, which was higher than the minimum ground clearance of $30 \mathrm{~mm}$ specified in the rules of the pico-EV competition.

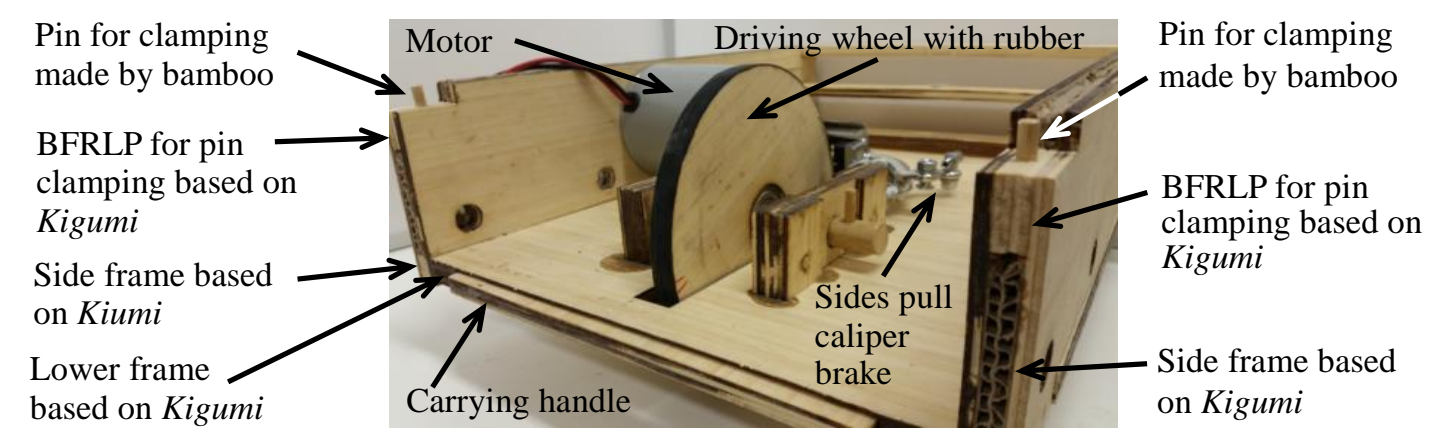

Fig.12 Example of Kigumi which Japanese traditional timberwork technology for side and lower frame using pin made by bamboo.

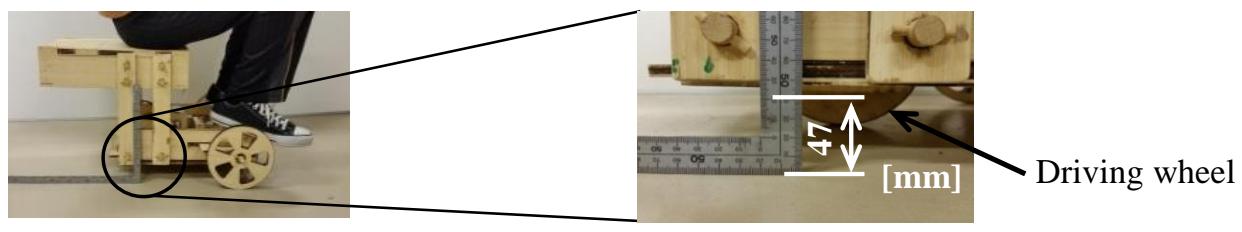

Fig.13 Static bending deflection was $1 \mathrm{~mm}$ when a driver on PGM-2015. The measured ground clearance was 47 $\mathrm{mm}$, which was specified in the rules of the pico-EV competition. The GCHM is effective in terms of rigidity and strength. 


\subsection{Mechanism of built-in handles}

To realize a carry-bag-type PGM-2015 tricycle, a carrying handle was built into the lower frame shown in Fig. 10. In concrete, a groove along which the handle can move approximately $300 \mathrm{~mm}$ was made in the lower frame, as shown in Figs. 14 (a) and 14 (b).

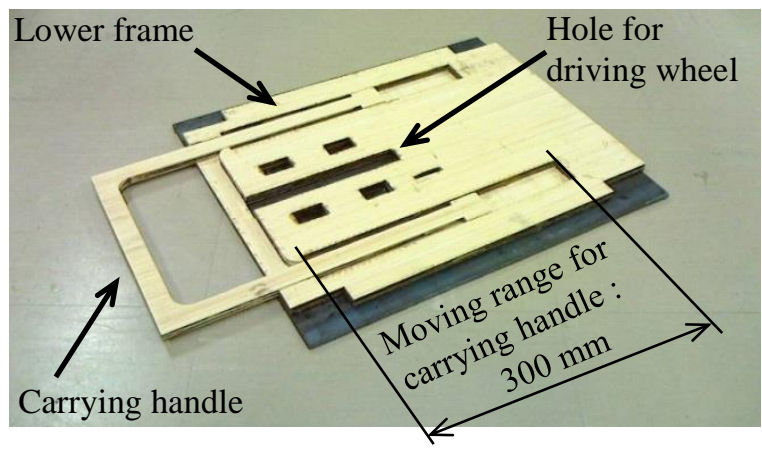

(a) Built-in structurer of carrying handle onto lower frame.

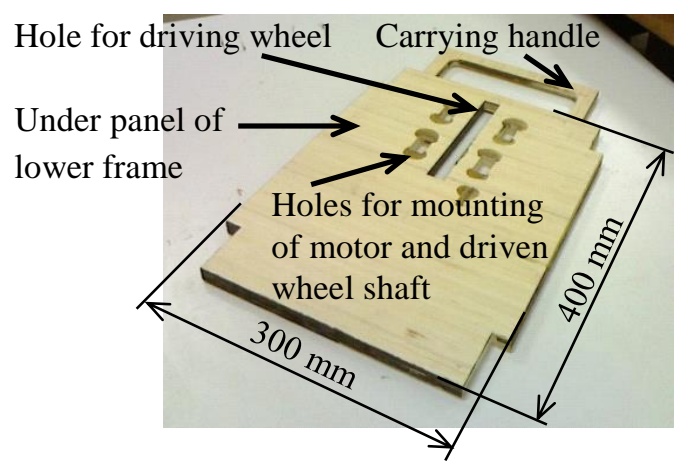

(b) Under view for panel of lower frame within carrying handle.

Fig.14 Mechanism for built-in carrying handle onto lower frame was shown. A groove along which the handle can move approximately $300 \mathrm{~mm}$ was made in the lower frame.

Similarly, the steering handle was built into the seat and the upper frame shown in Fig. 10. As shown in Fig. 15 (a), slide rails were formed so that the steering handle can move $250 \mathrm{~mm}$ along the rails, enabling a stretchable handle structure. To prevent the steering handle from slipping out of the slide rails, T-shaped stoppers were installed at the lower ends of the steering handle. Moreover, pins were installed at the lower ends of the slide rails, as shown in Fig. 15 (b), to enable the operation of the steering handle in connection with a steering knuckle arm.

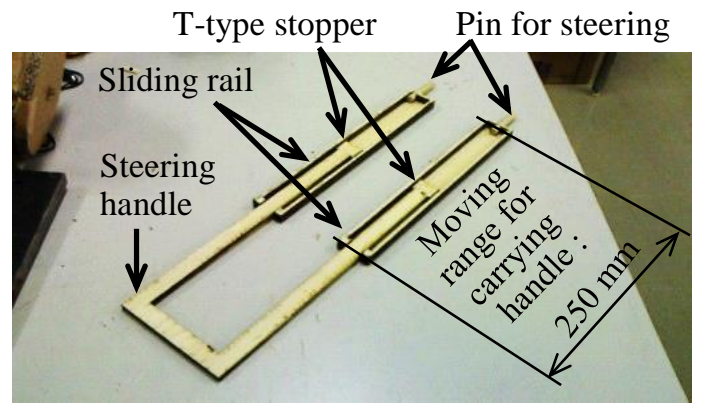

(a) Inner structure for steering handle with sliding rail.

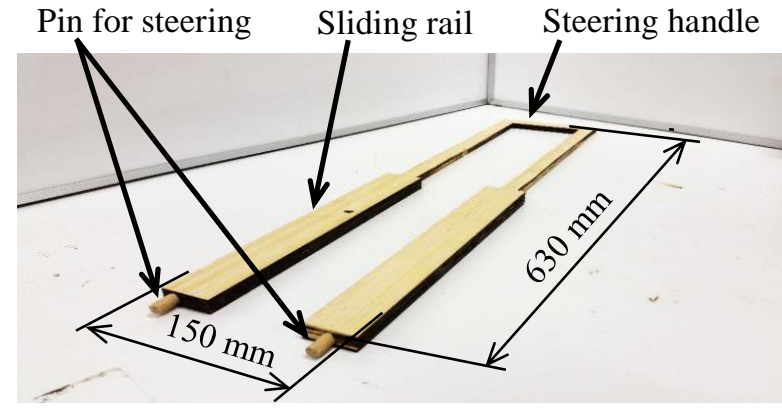

(b) Over view for steering handle.

Fig. 15 Mechanism for built-in steering handle was shown. Slide rails were formed so that the steering handle can move $250 \mathrm{~mm}$ along the rails. Pins were installed at the lower ends of the slide rails.

\subsection{Mounts for motor and driving wheel shaft}

To realize a PGM-2015 tricycle with a reduced weight and a simple structure, the mounts for the motor and the driving wheel shaft were integrated, as shown in Figs. 16 (a1), 16 (b1), and 16 (c1). Figure 16 (a1) shows the center mount for the motor and the driving wheel shaft, Fig. 16 (b1) shows the sidewall mount for the driving wheel shaft, and Fig. 16 (c1) shows the outer mount that holds the center and sidewall mounts. The outer mount is incorporated into the upper and lower sides of the lower frame of the PGM-2015 tricycle body and fixed using pins, as shown in Figs. 16 (a2) and 16 (b2). As a result, the outer mount extends $10 \mathrm{~mm}$ below the lower frame, as shown in Fig. 16 (c2). 
(a1) Center mounts for motor shaft and driving wheel shaft.

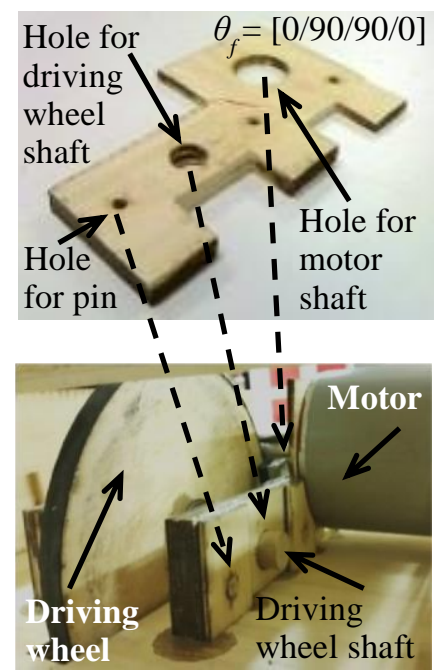

(a2) Mounted condition for motor and driving wheel shaft. (b1) Side mount for driving wheel shaft.

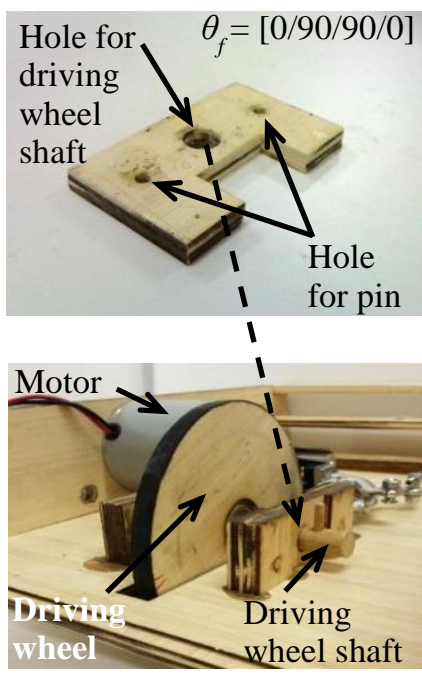

(b2) Mounted condition for driving wheel shaft. (c1) Outer mount hold between center and side mounts.

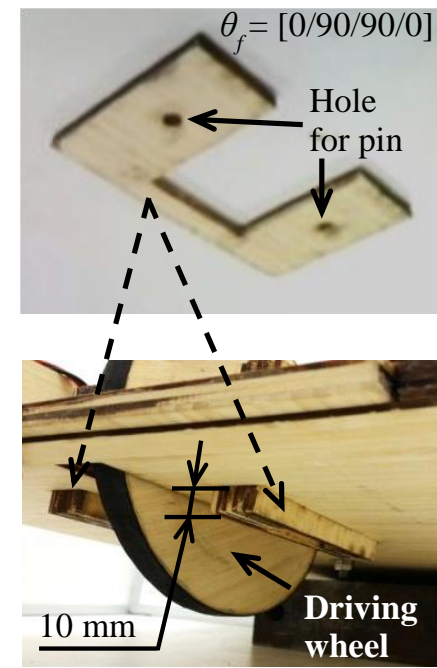

(c2) Under view for integrated mount.

Fig.16 Integrated mounting parts for motor and wheel shaft were shown. Since, driving wheel shaft, motor shaft and pin were inserted to each holes, integrated mount was completed.

\subsection{Driving method}

As shown in Fig. 17, a friction-based driving method was adopted. In this method, the motor shaft and the outer surface of the rear driving wheel were placed in contact. The motor shaft was covered with emery cloth using an adhesive paste. The outer surface of the driving wheel made of BFRLP was coated with a thin rubber layer using double-sided tape to increase the coefficient of friction between the motor shaft and the driving wheel and ensure the driving force. A KM77-0712 motor manufactured by Tsugawa Factory (Tsugawa Factory Products Catalogue (2016), 2016) was used, which had a rated output of $70 \mathrm{~W} / 12 \mathrm{~V}$, a mass of $1 \mathrm{~kg}$, a diameter of $\phi 77 \mathrm{~mm}$, a length of $100 \mathrm{~mm}$, and a rotation rate of $2500 \mathrm{rpm} \pm 10 \%$. The driving wheel consisted of five laminated BFRLPs with $\theta_{f}=$ [0/72/144/216/288]. The front wheel was similar to the driving wheel.

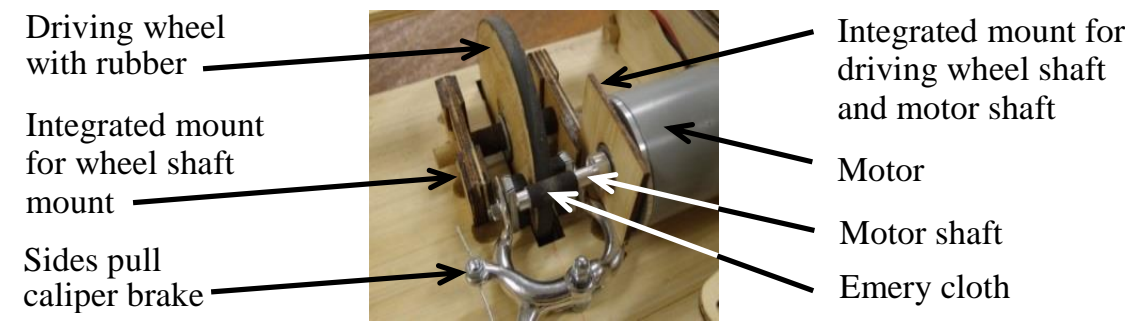

Fig.17 Friction driven system. The motor shaft and the outer surface of the rear driving wheel were placed in contact.

\subsection{Assembly procedure}

Figures 18 (a) -18 (e) are shown the assembly procedure of PGM-2015. It can be moved in a carry-bag form by holding the carrying handle, as shown in Fig. 18 (a). To assemble PGM-2015, first, place it horizontally and insert the carrying handle into the seat, as shown in Fig. 18 (b). Then, pull out the built-in steering handle stored under the seat and rotate and pull the seat upward to allow the driver to be seated, as shown in Fig. 18 (c). Finally, install the steering handle, as shown in Fig. 18 (d). PGM-2015 is now ready for use, as shown in Fig. 18 (e). It takes only 5 min to assemble the PGM-2015 because of its simplified structure. The total weight of PGM-2015 is $5.6 \mathrm{~kg}$. 


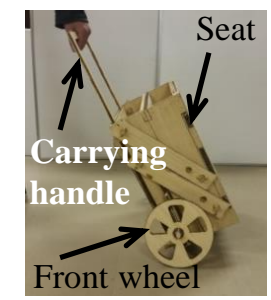

(a) Carry bag form.
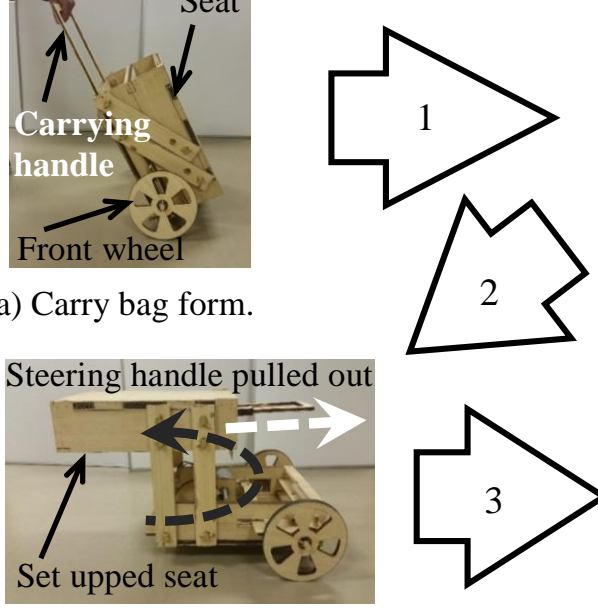

(c) Set up for seat and steering handle.

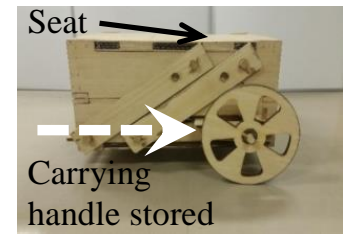

(b) Horizontal state and carrying handle stored.

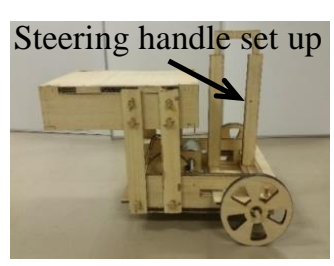

Driver seated and operating

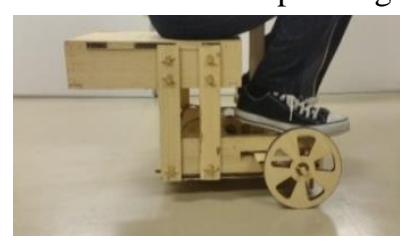

(e) Travelling form for PGM-2015.

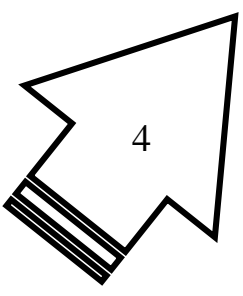

(d) Set up for steering handle.

Fig.18 Assembly procedure from carry bag form to PGM-2015 were shown. Carrying handle was stored, steering handle was pulled out and set upped, and then, travelling form, PGM-2015, was completed.

\section{Evaluation of developed PGM tricycle and design education}

The material cost of PGM-2015 was higher than the cost given in the design requirements in Table 1 but was less than JPY 30,000, suggesting that it can be produced cheaply. The reason in which cost differed from the initial plan listed in Table 1 is because a design change occurs plentifully and the mechanism became complicated. PGM-2015 can withstand a load of up to $100 \mathrm{~kg}$, exceeding the design requirement. The reason in which withstand load differed from the initial plan listed in Table 1 can consider the strength of axle shaft for a driving wheel was increased. Our team participated in the pico-EV Eco Challenge competition (pico-EV Eco Challenge 2015, 2015) with PGM-2015, which was entered in the design and technology categories. The average traveling velocity was $1.31 \mathrm{~km} / \mathrm{h}$ for $30 \mathrm{~min}$ of driving. Although this was slightly higher than the required velocity, the driver did not feel uneasy during the driving operation itself. PGM-2015 is considered to have no major problems in terms of strength and rigidity during traveling and is expected to be feasible for practical use. Our team KAIT was given the best design award (pico-EV Eco Challenge 2015, 2015) for the design and manufacture of the simple, inexpensive, lightweight, and small PGM-2015 tricycle using the biodegradable vegetable fiber material consisting of bamboo and RCF. Thus, the design requirements shown in Table 1 were satisfied. This was the achievement of an undergraduate student in our laboratory over one year, who devised two important ways of simplifying the structure and realized the use of the biodegradable material.

\section{History of development of PGM tricycles at Kanagawa Institute of Technology}

Figures 19 (a) to (c) and Figures 20 (a) and (b) shows photographs of the PGM tricycles developed at KAIT. Figure 19 (a) shows the first prototype PGM, in which raw bamboo and a solar panel were used. Figure 19 (b) shows the high-rigidity frame of an eco-run vehicle frame using bamboo-laminated lumber. Figure 19 (c) shows PGM using bamboo fiber cross-ply laminated plates and laminated lumber. Figure 20 (a) shows PGM using BFRLPs with arbitrarily arranged bamboo fibers. Figure 20 (b) shows PGM using GCHM.

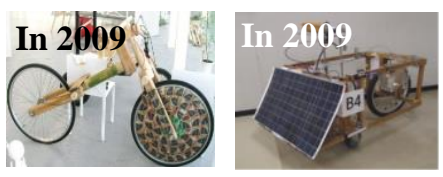

(a) Prototype PGM

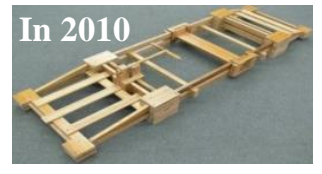

(b) Eco-run frame
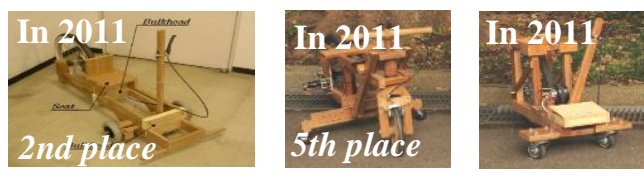

(c) Basic PGM tricycle

Fig. 19 PGM histories of KAIT were shown. Using raw bamboo, a solar panel, bamboo-laminated lumber, and BFRLP with arbitrarily arranged bamboo fibers. 

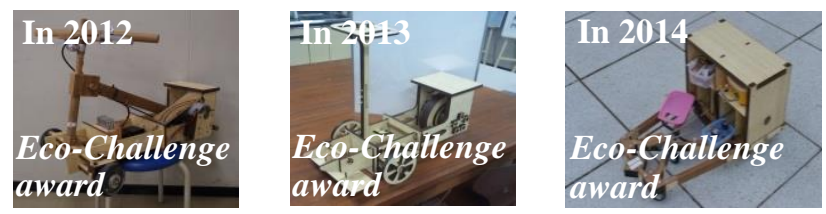

(a) PGM using BFRLPs with arbitrarily arranged bamboo fibers.

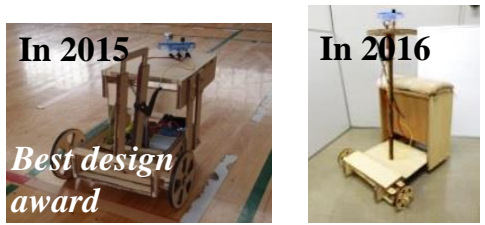

(b) PGM using GCHM.

Fig. 20 PGM tricycle histories of KAIT were shown. Using BFRLPs, RCF and GCHM.

\section{Proposed use of PGM tricycles to realize calmer towns and more pleasant society}

Vehicles are one of the major foundations of modern society. In Japan's aging society, there are very few inexpensive, ultra-small, and lightweight vehicles that have simple functions, can safely travel at a low velocity, and help the elderly go shopping and travel. If low-price vehicles that do not travel on public roads but can run at an ultralow velocity in limited areas, such as in local communities, homes, and department stores, are manufactured and sold, the elderly will be able to lead a more useful life. City planning that allows such transportation should also be discussed. Considering the current environmental impact on the global environment, future vehicles should be made of biodegradable vegetable fiber materials similarly to our PGM tricycles. The Kigumi technology should also be utilized to join wood members, which will contribute to the continuation of traditional technology in Japan. Projects based on the concept of making future vehicles from vegetable (Yano, 2014) should be intensively promoted.

To realize low-price vehicles and reduce environmental impact, large production facilities should be avoided. The design and technology of currently available vehicles are extremely complicated. New designs and technologies for simplifying the structure are required. It is necessary to reconsider the roles of vehicles and the traffic and transportation systems in accordance with their purposes as well as the materials used for vehicle body structures.

We will promote projects aiming to realize the concept of PGMs of the future so that people can enjoy a better quality of life, which will contribute to the development of a more pleasant society.

\section{Conclusions}

Our newly developed GCHM was applied to the PGM-2015 tricycle, which is inexpensive and will be useful for the elderly. The following are the main results obtained.

(1) The GCHM was found to be practically applicable to the PGM-2015 tricycle in terms of both strength and rigidity.

(2) The weight of the body structure of the PGM-2015 tricycle using the GCHM was reduced by $21 \%$ to $4.2 \mathrm{~kg}$. The total weight of the PGM tricycle was $5.6 \mathrm{~kg}$. Therefore, the GCHM can be used to reduce the weight of the body of the PGM tricycle.

(3) The mechanism by which the vehicle is converted from the carry-bag form to the traveling form facilitates the carrying of the PGM-2015 tricycle.

(4) Owing to the simplified structure, it takes only $5 \mathrm{~min}$ to assemble the vehicle, and the vehicle can easily be assembled by the elderly.

(5) We described our vision of how the PGM tricycles can be used for the development of calmer towns and a more pleasant society.

\section{Acknowledgment}

The PGM-2015 tricycle shown here was mainly developed by Naoki Watanabe, who was an undergraduate student of the Department of Vehicle System Engineering, Kanagawa Institute of Technology, with the assistance of Takuma Nagasawa. We sincerely express our gratitude to their effort and enthusiasm. 


\section{References}

Abhijit P. Deshpande, M. Bhaskar Rao, and C. Lakshmana Rao, Extraction of bamboo fibers and their use as reinforcement in polymeric composites, Journal of Applied Polymer Science, Vol. 76, No. 1,(2000), pp. 83-92 (Wiley Online Library), available from < http://onlinelibrary.wiley.com/doi/10.1002/(SICI)1097-4628 (20000404)76:1\% 3C83::AID-APP11\%3E3.0.CO;2-L/full>, (accessed on 18 January , 2017).

Amada S., Mechanical Structure of Bamboo Based on Natural Functionally Graded Materials-2nd Report, Fundamental Mechanical Properties, Bamboo Journal, Vol. 15 (1998), pp. 31-39 (in Japanese).

Carpenters' tools study group, Technique of Kigumi, joint, and sparring, Seibundo-shinkosha Ltd. (2014) (in Japanese).

Dia Bamboo Products Catalogue, Dia Fusou Ltd., Japan, (online), available from <http://www.dia-f. co.jp/product/ index.html>, (accessed on 13 January, 2017) (in Japanese).

Fujikawa M., Nishikawa A., Tanaka K., and Inoue M., Fundamental Study on Development of Denisified Bamboo Plywood -Part 2 Product of 5-ply Bamboo LVL and Bending Performance -, Proceeding of 45th Architectural Institute of Japan Annual Meetings (Kyushu branch) (2006), pp. 293-296 (in Japanese).

GREMO, Green Mobility Research Institute, Institutes of Innovation for Future Society, Nagoya University (2016), (in Japanese), (online), available from <http://www.gremo.mirai.nagoya-u.ac.jp/ >, (accessed on 13 October, 2016).

Material of Green Mobility, What is a Green Mobility (2015), (online), available from <http://green-mobility.jp/about/ >, (accessed on 13 October, 2016) (in Japanese).

Material of Smart Wellness City which create health and happiness protracted-life society (2015), (online), available from <http://www.twr.jp/swc/page2.html>, (accessed on 13 October, 2016) (in Japanese).

pico-EV Eco Challenge 2015 sponsored by JSME, (online), available from < http:// www.nbu.ac.jp/ picoev /_picoev2015 >, (accessed on 13 October, 2016) (in Japanese).

Ramirez F., Maldonado A., Correal J. F., and Estrada M., Bamboo-Guadua Angustifolia Kunt Fibers for Green Composites, Proceedings of 18th International Conference on Composite Materials, (2011), pp. 1-4.

Road traffic policy organic act (2013), Ministry of Land, Infrastructure, Transport and Tourism of Japan, (online), available from < http://www.mlit.go.jp/sogoseisaku/transport_policy/sosei_transport_policy _tk1_000010.html $>$, (accessed on 13 October, 2016) (in Japanese).

Sanyo Package System Products Catalogue, (online), available from <http://www.sanpake.co.jp/>, (accessed on 13 October, 2016) (in Japanese).

Takahashi Y. and Uda K., Ultra-Small Electric Vehicle Competition Using Small Rechargeable Batteries - pico-EV Eco Challenge 2012-, Proceedings of 2012 International Conference on Control, Automation and Systems, Paper No. WD09-6, pp. 498-503.

Tokoro R., Duc Minh Vu, Okubo K., Tanaka T., Fujii T., and Fujiura T., How to improve mechanical properties of polylactic acid with bamboo fibers, Journal of Material Science, Springer, Vol. 43 (2008) , pp. $775-787$ (DOI 10.1007/s10853-007-1994-y).

Tsugawa Factory Products Catalogue (2016), (online), available from <http://www.tsugawa.co.jp/>, (accessed on 13 October, 2016) (in Japanese).

Uda K., Takahashi Y., Development of Ultra Small Electric Vehicle: pico-EV using Natural Bamboo Fiber Laminated Plates, 2013 JSME Conference on Robotics and Mechatronics in Tsukuba, Japan (2013), 2AP19 (in Japanese).

Uda K., Takahashi Y. and Fujisawa T., Production of Ultra-Lightweight and Small EV: pico-EV using Bamboo Fiber Laminated Plates, Vol. 49, No. 6 (2014), pp.311-316 (in Japanese).

Uda K., Relationship Between Fiber Orientation Angle and Static Bending Characteristic of Laminated Bamboo Plates, Proceedings of the 20th International Conference on Composite Materials (ICCM20) (2015), Paper No.1108-2, (online), available from < http://www. iccm20.org/p/ >, (accessed on 13 October, 2016).

Yano H., The vehicle of the future is made from a vegetable, Proceedings of the 200th Symposium for Survival Area and the 7th Project for Bio Materials (2012), (online), available from <http://www.rish. kyoto-u. ac.jp/ labm/wp-content/uploads/2013/01/nedo-gsc2012.pdf\#search>, (accessed on 13 October, 2016) (in Japanese).

Yearbook for JSAE, Buss (Synthesis), Journal of Society of Automotive Engineers of Japan, Vol. 69, No. 8 (2015b), pp.50- 55 (in Japanese).

Yearbook for JSAE, Gasoline-powered vehicle, Diesel vehicle, Hybrid electric vehicle, Fuel-cell vehicle, Journal of Society of Automotive Engineers of Japan, Vol. 69, No. 8 (2015a), pp. 88- 98 (in Japanese). 